\title{
Eight Weeks of Aerobic Interval Training Improves Psychomotor Function in Patients with Parkinson's Disease-Randomized Controlled Trial
}

\author{
Jarosław Marusiak ${ }^{1, *}$ (D) Beth E. Fisher ${ }^{2}$, Anna Jaskólska ${ }^{1}$, Krzysztof Słotwiński ${ }^{3}$, \\ Sławomir Budrewicz ${ }^{3}$, Magdalena Koszewicz ${ }^{3}$, Katarzyna Kisiel-Sajewicz ${ }^{1}$, \\ Bartosz Kamiński ${ }^{1}$ and Artur Jaskólski ${ }^{1}$ \\ 1 Department of Kinesiology, Faculty of Physiotherapy, University School of Physical Education, \\ Al. I.J. Paderewskiego 35, Building P4, 51-612 Wroclaw, Poland; anjaskol@gmail.com (A.J.); \\ katarzyna.kisiel-sajewicz@awf.wroc.pl (K.K.-S.); bartekaminski1991@gmail.com (B.K.); \\ artur.jaskolski@awf.wroc.pl (A.J.) \\ 2 Division of Biokinesiology and Physical Therapy and Department of Neurology, \\ University of Southern California, Los Angeles, CA 90033, USA; bfisher@usc.edu \\ 3 Department of Neurology, Medical University of Wroclaw, 50-566 Wroclaw, Poland; \\ k.slot@gazeta.pl (K.S.); s.budrewicz@wp.pl (S.B.); magdalena.koszewicz@umed.wroc.pl (M.K.) \\ * Correspondence: jaroslaw.marusiak@awf.wroc.pl; Tel.: +48-71-347-3544; Fax: +48-71-347-3431
}

Received: 18 January 2019; Accepted: 7 March 2019; Published: 11 March 2019

\begin{abstract}
Background: This study examined the generalized effects of cycle ergometer aerobic interval training (AIT) on psychomotor behaviors in individuals with Parkinson's disease (PD), including bimanual motor control, cognitive function, and neurological motor and non-motor parkinsonian signs. Methods: Twenty mild to moderate PD patients were randomly allocated to the following groups: (1) trained group (PD-TR, $n=10$ ), which besides receiving usual care, underwent an 8-week moderate intensity AIT program; or (2) control group (PD-CO, $n=10$ ) which received usual care, including participation in conventional physical therapy. Both groups were tested before and after the 8-week AIT program period with the following assessments: (1) laboratory analyses of bimanual motor control, (2) psychological evaluation of cognitive function, and (3) an evaluation of neurological parkinsonian signs. Results: The PD-TR group exhibited improved (1) bimanual motor control, reflected by a decreased time $(p=0.013)$ and increased rate of grip force development $(p=0.013)$ in the manipulating hand and a decreased time delay between grip force initiation in the manipulating and stabilizing hand $(p=0.020)$; ( 2$)$ executive function, reflected by decreased performance time in part II of the Stroop Test $(p=0.007)$; and (3) neurological parkinsonian signs, reflected by an amelioration of upper-extremity bradykinesia $(p=0.015)$ and improvement in daily life manual functions $(p=0.004)$, mood, and intellectual function $(p=0.005)$. Conclusions: Following an 8 -week moderate intensity AIT program, patients with PD exhibited improved psychomotor behaviors, reflected by bimanual motor control, executive function, and neurological parkinsonian signs.
\end{abstract}

Keywords: Parkinson's disease; aerobic interval training; neuroplasticity; bimanual motor control; executive function

\section{Introduction}

Parkinson's disease (PD) is a progressive neurodegenerative condition characterized by dopamine (DA) depletion due to the degeneration of dopaminergic neurons in the substantia nigra pars compacta [1]. PD impacts motor and cognitive function secondary to the shared DA-dependent neural structures [2-6]. The gold standard treatment for Parkinson's disease is DA replacement 
pharmacotherapy, which does not stop the neurodegenerative process and has negative side effects [7]. According to previous reports on animal models of parkinsonism, high-intensity exercise induces both behavioral and neuroplastic changes, including an improvement in DA terminal function in the central nervous system (CNS) [8-13]. These findings have been partly translated to human studies [14-23], potentially revealing the basic mechanisms underlying numerous reports of exercise-induced motor and cognitive improvements in patients with PD [14-21,23]. Most human studies [14-17,21,22] have applied continuous intensive training. However, in previous studies [24-26], interval training has been shown to be more enjoyable and effective than continuous exercise programs in a non-PD population (healthy adults [24,25] and adult cardiological patients [26]). According to Zoladz et al. [20] and Marusiak et al. [23], moderate intensity aerobic interval training (AIT) has the potential to induce beneficial neuroplastic changes in the CNS in trained individuals with PD. In these studies [20,23], the AIT-induced increase in brain derived neurotrophic factor (BDNF) was demonstrated. However, the beneficial effects of moderate intensity AIT performed on a cycloergometer on symptoms and specific cognitive (executive function) and motor (automatic bimanual motor control) aspects of psychomotor behaviors in patients with PD have not been established. Therefore, in the current study, our primary outcomes were automatic bimanual motor control measures and the psychological evaluation of cognitive functions. Thus, in our PD patients, we tested performance of an anti-phase bimanual motor coordination task, because this task has been previously reported to be strongly dependent on dopaminergic function [2-6]. For the psychological cognitive function assessments, we primarily chose executive function tests, i.e., the trail making test (TMT) and the Stroop Test (ST) [27-31], because performance on these tests is related to DA-dependent striatocortical neuronal networks and executive function deficits in PD. These deficits include working memory, planning, and inhibitory control as well as episodic memory and visuospatial functioning [32]. These executive function deficits appear years before the cardinal motor symptoms allow clinical diagnosis (prodromal stage of disease) and worsen in PD dementia [32]. Our secondary outcome measures were neurological signs of PD, with a primary focus on aspects of the unified Parkinson's disease rating scale that concern precise one-handed and bimanual motor functions as well as cognitive aspects of non-motor symptoms. These neurological PD signs were chosen since they are related to the DA-dependent subcortical and cortical neural structures [2-6]. Thus, our goal was to study the generalized effects of moderate intensity AIT performed on a cycle ergometer by the lower extremities on DA-dependent psychomotor behaviors [2-6,27-31], including upper extremity automatic bimanual motor control, executive function as well as neurological motor and non-motor signs of PD. Our general hypothesis was that moderate intensity AIT could result in psychomotor behavioral improvement in trained individuals with PD, which would be reflected in the above mentioned primary and secondary outcome measures.

\section{Materials and Methods}

\subsection{Subjects}

Patients with idiopathic PD were recruited from the Clinic of Neurology at Medical University of Wroclaw (CN MUW) and from the Circle of Friends of People with Parkinson's Disease in Wroclaw. The inclusion criteria were age $>55$ years-old, diagnosis of idiopathic PD, and modified Hoehn and Yahr stages between 1.5 and 3. The exclusion criteria were (1) presence of other neurological disorders, (2) any cardiovascular or respiratory system restrictions and/or motor deficits that could limit performance in high-speed pedaling on a cycle ergometer or in conventional physical therapy, and (3) practicing any regular physical activity except for conventional physical therapy for PD. Compliance with the study criteria was assessed by the patients' medical records, a physician's interview, and a clinical neurological examination. The subjects were informed of the aim of the study and provided their written consent prior to the study, which was approved by the local Ethics Committee of the University School of Physical Education in Wroclaw (project identification code: 
0247/p01/2010/70) and in accordance with the Code of Ethics included in the Helsinki Declaration. Our study protocol was registered as a clinical trial (ClinicalTrials.gov identifier: NCT03753503).

Twenty-two patients with PD were initially enrolled to participate in our study, and two patients were excluded due to health problems $(n=1)$ and family problems $(n=1)$ (Figure 1$)$. According to the Hoehn and Yahr scale (H\&Y) [33], all PD patients were mildly to moderately affected (H\&Y score of 1.5-3.0) (Table 1). The 20 patients were randomly allocated into one of two groups: the training group (PD-TR, $n=10$ ) or the control group (PD-CO, $n=10$ ) (Figure 1) (Table 1). Based on previously published data $[20,21,23]$, we statistically estimated that a sample size of 10 per group would be sufficient to test our hypotheses and obtain statistically significant results. The whole block type randomization process was carried out by the authors of this study using sequentially numbered sealed envelopes. Opaque envelopes were used to conceal allocation. Patients randomized to the PD-CO group were asked to maintain their usual lifestyle during the study period and received usual care including participation in conventional physical therapy that did not involve moderate or high intensity aerobic interval training on a cycle ergometer or treadmill. Patients randomized to the PD-TR group, in addition to usual care (including their participation in a conventional physical therapy), participated in an 8-week moderate intensity AIT program involving exercise three times a week on a stationary cycle ergometer.

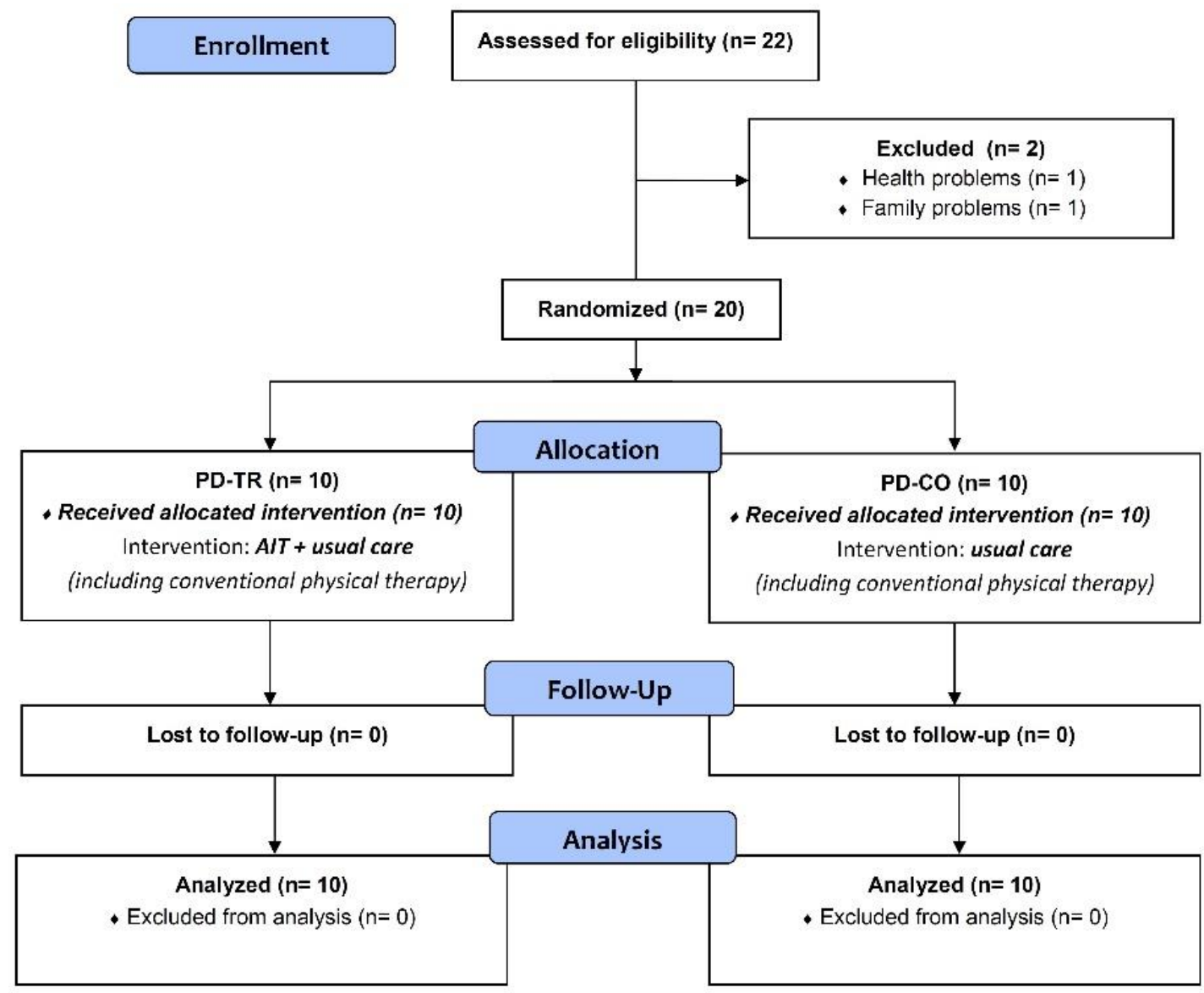

Figure 1. Flow diagram. 
Table 1. Clinical and anthropometric characteristics of the Parkinson's disease (PD) patients in the training (PD-TR, $n=10$ ) and control (PD-CO, $n=10$ ) groups.

\begin{tabular}{|c|c|c|c|c|c|c|c|c|}
\hline $\begin{array}{c}\text { PD Patient } \\
\text { No. }\end{array}$ & $\begin{array}{c}\text { Age } \\
\text { (Years) }\end{array}$ & $\begin{array}{c}\text { Sex } \\
(\mathrm{F} / \mathrm{M})\end{array}$ & $\begin{array}{c}\text { Body } \\
\text { Mass (kg) }\end{array}$ & $\begin{array}{l}\text { Height } \\
\text { (cm) }\end{array}$ & $\begin{array}{c}\text { Disease } \\
\text { Onset/Duration } \\
\text { (Years) }\end{array}$ & $\begin{array}{c}\text { Affected } \\
\text { Upper Limb } \\
(\mathrm{R} / \mathrm{L})\end{array}$ & $\begin{array}{l}\text { Dominant } \\
\text { Upper Limb } \\
\text { (R/L) }\end{array}$ & $\begin{array}{l}\text { Hoehn } \\
\text { and Yahr } \\
\text { (Points) }\end{array}$ \\
\hline PD-TR\#01 & 79 & M & 71 & 157 & $69 / 10$ & $\mathrm{R}$ & $\mathrm{R}$ & 2.5 \\
\hline PD-TR\#02 & 65 & $\mathrm{~F}$ & 64 & 162 & $58 / 7$ & $\mathrm{~L}$ & $\mathrm{R}$ & 2.5 \\
\hline PD-TR\#03 & 68 & M & 78 & 167 & $55 / 13$ & $\mathrm{R}$ & $\mathrm{R}$ & 2.5 \\
\hline PD-TR\#04 & 65 & $\mathrm{~F}$ & 61 & 155 & $63 / 2$ & $\mathrm{R}$ & $\mathrm{R}$ & 1.5 \\
\hline PD-TR\#05 & 60 & M & 79 & 169 & $46 / 14$ & $\mathrm{R}$ & $\mathrm{R}$ & 3.0 \\
\hline PD-TR\#06 & 84 & M & 73 & 165 & $80 / 4$ & $\mathrm{~L}$ & $\mathrm{R}$ & 1.5 \\
\hline PD-TR\#07 & 68 & M & 67 & 177 & $56 / 12$ & $\mathrm{~L}$ & $\mathrm{R}$ & 2.5 \\
\hline PD-TR\#08 & 78 & $\mathrm{~F}$ & 67 & 159 & $70 / 8$ & $\mathrm{~L}$ & $\mathrm{R}$ & 3.0 \\
\hline PD-TR\#09 & 62 & M & 63 & 161 & $46 / 16$ & $\mathrm{R}$ & $\mathrm{R}$ & 3.0 \\
\hline PD-TR\#10 & 88 & $\mathrm{~F}$ & 67 & 149 & $84 / 4$ & $\mathrm{~L}$ & $\mathrm{R}$ & 2.0 \\
\hline Mean \pm SD & $72 \pm 10$ & - & $69 \pm 9$ & $162 \pm 8$ & $63 \pm 13 / 9 \pm 5$ & - & - & $2.35 \pm 0.57$ \\
\hline PD-CO\#01 & 81 & $\mathrm{~F}$ & 63 & 159 & $71 / 10$ & $\mathrm{~L}$ & $\mathrm{R}$ & 3.0 \\
\hline PD-CO\#02 & 67 & $\mathrm{~F}$ & 64 & 156 & $63 / 4$ & $\mathrm{R}$ & $\mathrm{R}$ & 2.0 \\
\hline PD-CO\#03 & 81 & M & 67 & 157 & $59 / 12$ & $\mathrm{R}$ & $\mathrm{R}$ & 2.0 \\
\hline PD-CO\#04 & 90 & $\mathrm{~F}$ & 60 & 148 & $84 / 6$ & $\mathrm{~L}$ & $\mathrm{R}$ & 2.0 \\
\hline PD-CO\#05 & 79 & $\mathrm{~F}$ & 60 & 156 & $69 / 8$ & $\mathrm{~L}$ & $\mathrm{R}$ & 2.5 \\
\hline PD-CO\#06 & 72 & M & 78 & 182 & $61 / 11$ & $\mathrm{R}$ & $\mathrm{R}$ & 2.0 \\
\hline PD-CO\#07 & 60 & $\mathrm{~F}$ & 67 & 153 & $52 / 8$ & $\mathrm{R}$ & $\mathrm{R}$ & 2.0 \\
\hline PD-CO\#08 & 74 & $\mathrm{~F}$ & 59 & 164 & $69 / 5$ & $\mathrm{R}$ & $\mathrm{R}$ & 1.5 \\
\hline PD-CO\#09 & 66 & $\mathrm{~F}$ & 70 & 160 & $64 / 2$ & $\mathrm{~L}$ & $\mathrm{R}$ & 1.5 \\
\hline PD-CO\#10 & 70 & M & 76 & 166 & $55 / 15$ & $\mathrm{R}$ & $\mathrm{R}$ & 3.0 \\
\hline Mean \pm SD & $74 \pm 9$ & - & $66 \pm 7$ & $160 \pm 9$ & $66 \pm 9 / 8 \pm 4$ & - & - & $2.25 \pm 0.53$ \\
\hline
\end{tabular}

Abbreviations: No.—number; F—female; M-male; R—right side; L—left side; \pm SD—standard deviation.

\subsection{Experimental Procedures}

Both groups were tested twice at the motor control laboratory of the Department of Kinesiology at the Faculty of Physiotherapy University School of Physical Education in Wroclaw (DKFP USPEW) before the eight week period of AIT (PRE) and after that time period (POST), i.e., within 6-10 days after the final AIT session, to ensure that the measurement outcome values in the PD-TR group were not due to the effects of the final single training session. The 8-week AIT program for PD-TR group was carried out in the facilities of the DKFP USPEW. The PD-CO group maintained their normal daily physical activity during this eight week time period (parallel design), receiving only usual care, including conventional physical therapy as prescribed and provided by the National Health Fund of Poland, which included activities for improving motor control, but without any kind of moderate or high intensity aerobic interval or continuous physical training (example: cycle ergometer, treadmill, or Nordic walking training). The patients were asked to keep an activity log (that was checked by investigators) to avoid changes in lifestyle during the project's time frame. During the PRE and POST testing sessions, all PD patients underwent (i) motor control recording and analysis of performance in an anti-phase bimanual task using our custom-made device, (ii) a psychological evaluation of cognitive function, and (iii) a neurological assessment of PD motor and non-motor signs. The time of day for the two testing sessions (PRE and POST) was consistent for all tested subjects. All tested subjects were familiarized with the experimental protocol prior to participation in each testing session. During both testing sessions, all patients with PD were in their medication off-phase, i.e., the testing was carried out after withdrawal of anti-parkinsonian drugs for $12 \mathrm{~h}$ overnight. Since we assumed that the beneficial AIT effects on psychomotor function would be associated with neuroplasticity-induced improvement in dopaminergic function, we decided to test the patients with PD in their medication off-phase, i.e., without the dopaminergic treatment's influence on dopamine level. However, during the intervention period (eight weeks of AIT program and usual care in PD-TR or eight weeks of usual care in PD-CO), the patients in both groups were in their medication on-phase, i.e., at least one hour after taking their normal daily dosage of anti-parkinsonian medication when they subjectively felt energetic. The medication doses were constant throughout this 8-week period and remained the same as those normally prescribed by their leading neurologist. We provided all patients with transportation 
to the testing sessions, and all patients from the PD-TR group were transported to each training session. The training supervisor monitored patients' attendance to the AIT program.

\subsection{Aerobic Interval Training Protocol}

The 8-week AIT program consisted of three weekly $1 \mathrm{~h}$ training sessions (each consisting of a $10 \mathrm{~min}$ warm-up, $40 \mathrm{~min}$ of a moderate intensity aerobic interval exercise, and a $10 \mathrm{~min}$ cool-down phase at a slow voluntary speed) performed on a stationary cycle ergometer (MONARK, Ergomedic 874E, Vansbro, Sweden) that measured cadence (revolutions per minute, rpm) and power (W). During each training session, the 40-min aerobic interval exercise consisted of 8 sets of 5 min intervals, including $3 \mathrm{~min}$ of cycling at $\geq 60 \mathrm{rpm}$ but preferably at 80-90 rpm (fast phase of interval) and $2 \mathrm{~min}$ of cycling at $\leq 60 \mathrm{rpm}$ (slow phase of interval). The patients in the PD-TR group were encouraged to cycle faster (80-90 rpm or 30\% faster than their voluntary pedaling rate) during the fast phase of interval and were rhythmically cued by a metronome and verbally encouraged by an instructor to pedal with the appropriate speeds for the fast and slow phases. The cadence values were presented to each subject in real-time on a screen as feedback to control the rpm during the different interval phases. The heart rate (HR, beats per minute, bpm) measured using a Polar system (Polar, Kempele, Finland), cadence (rpm), and power $(\mathrm{W})$ were monitored and collected during each training session. The training supervisor adjusted the resistance for each patient to ensure they were cycling at their target heart rate (THR) and at an appropriate speed. PD patients cycled at $60-75 \%$ of their individualized $\mathrm{HR}_{\max }$ (maximal heart rate), which was predicted for each patient based on the formula developed by Tanaka et al. [34]. The PD patients were encouraged to increase their THR every 2 weeks by $5 \%\left(60 \%\right.$ of the $\mathrm{HR}_{\max }$ during weeks $1-2,65 \%$ during weeks $3-4,70 \%$ during weeks $5-6$, and $75 \%$ during weeks $7-8$ of the training period). The averaged values of the percentage of $\mathrm{HR}_{\max }$, cadence, and power of the eight intervals for each training session for each subject during the fast and slow phases of AIT were calculated. Then, the average value of the 24 training sessions for each parameter was calculated. Additionally, the patients' perceptions of the exercise intensity (for the fast and slow phases of the interval) were assessed using the Borg Rating of Perceived Exertion (RPE) scale [35].

\subsection{Primary Outcomes}

\subsubsection{Bimanual Motor Control Recording and Analysis}

The bimanual motor control recordings and analyses were performed by the same investigator (from the DKFP USPEW) during both testing sessions, who was not blinded to the groups tested. The PD patients were asked to perform an anti-phase bimanual motor coordination task using our custom-made device (Figure 2), which is a modification of the device used in other studies [21,36]. This motor task is an imitation of a daily life bimanual task, similar to that performed when a person opens a rectangular container of perfume by pulling (without rotation) the rectangular cap of the container with one hand (manipulating hand) while stabilizing the lower rectangular part of the container with the second hand (stabilizing hand). During the testing sessions, the patients performed this task while sitting in a chair with their forearms comfortably resting on a table, and the measurement device was placed at the midline between the two hands (Figure 2A). Our device consists of the following three modules (Figure 2B): (1) two identical modules that measure the normal grip force (GF; squeezing between the thumb and second to fifth fingers), i.e., the upper module was for the manipulating hand $\left(\mathrm{GF}_{\mathrm{man}}\right)$ and the bottom module was for the stabilizing hand $\left(\mathrm{GF}_{\mathrm{stab}}\right)$, and (2) a middle module, positioned between the upper and bottom modules, which measured the load force (LF), i.e., the extension tangential force generated by both hands pulling against each other to overcome the device's resistance. 


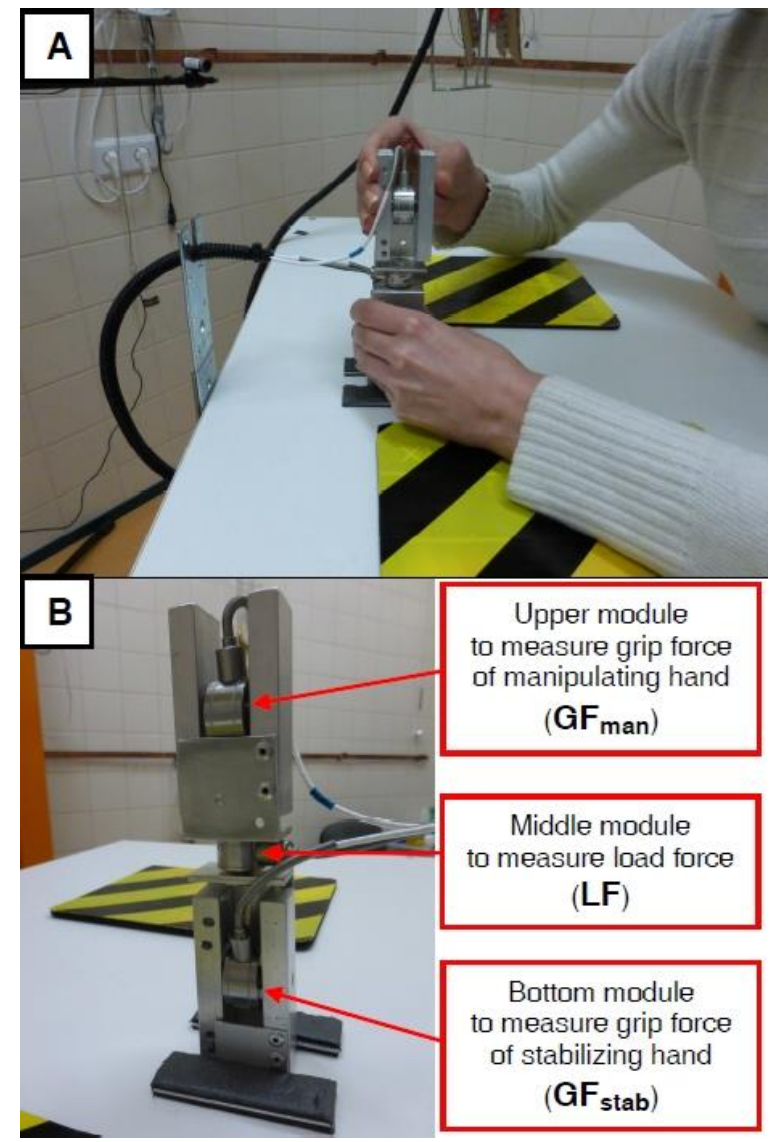

Figure 2. Images describing the set-up (panel A) and our custom-made device (panel B) used for the anti-phase bimanual motor control measurements.

The experimental motor task consisted of the following sequential motor activities performed by an instructed subject (all subjects received the same instructions) after an auditory signal: (i) moving both hands toward the measurement device, (ii) squeezing the upper module with the more affected hand and the bottom module with the less-affected hand, and (iii) generating the LF, i.e., "pulling isometrically" - pulling the upper and bottom modules in opposite directions while avoiding movement of the measurement device. Appropriate performance in the LF generation task requires synchronized automatic coordination between the hand that simultaneously squeezes and pulls the upper module (manipulating hand) and the hand that stabilizes the device by simultaneous squeezing and pulling on the lower module (stabilizing hand). Because the neural substrates of this automatic bimanual motor coordination and feed forward control to adjust GFs to LF are dopamine-dependent extra pyramidal structures (striatum) and cortical areas (pre-motor areas) [2,3,5], we hypothesized that this bimanual task paradigm could be a sensitive experimental method to indirectly assess any AIT-induced CNS improvement in our PD patients, as reported in other studies [21,36].

The subjects performed three trials of maximal isometric LF generation (separated by 3 min resting intervals) from which we calculated an averaged value of maximal voluntary contraction (MVC) of LF. After a 3 min rest, the subjects performed three trials of $20 \%$ MVC of isometric LF generation with a 2 min interval between trials. The force feedback provided to the subject (on the LCD screen) during the three $20 \%$ MVC of LF trials included the actual generated LF signal and a horizontal cursor indicating the set target of $20 \%$ MVC of LF that must be achieved during each trial.

To assess the automatic (subconscious) adjustment control of GF at 20\% MVC of LF, we primarily analyzed the following three parameters: peak value of GF in the manipulating hand (GFman), time taken for $\mathrm{GF}_{\text {man }}$ development (time $\mathrm{GF}_{\text {man }} \mathrm{dev}$ ), and rate of $\mathrm{GF}_{\text {man }}$ development (rate $\mathrm{GF}_{\text {man }}$ dev). The possible AIT-induced changes in the parameters describing the automatic adjustment of 
GF to LF might also be related to inter-group and inter-testing session differences in the ability to generate a maximal level of LF (100\% LF) and consequently, to differences in the values of parameters describing the generation of $20 \%$ LF. These are the following parameters: the absolute value of LF ( $20 \% \mathrm{LF}$ ), and the time taken and rate of $20 \%$ LF development (time $20 \% \mathrm{LF}$ dev and rate $20 \% \mathrm{LF}$ $\mathrm{dev}$ ). Therefore, to rule out any changes in LF control from the assessment of GF adjustment to LF, we additionally analyzed these load force parameters.

To assess the quality of automatic bimanual inter-limb coordination, we analyzed the delay between the onset of GF development in the manipulating hand and that in the stabilizing hand (time GFs del man-stab). For more details regarding the description of our custom-made device as well as the data recording, processing, and analysis, see the text in Supplementary file S1.

\subsubsection{Psychological Assessment of Cognitive Function}

All PD patients were evaluated by an experienced psychologist (investigator from the CN MUW) who was blinded to the tested groups. The investigator primarily assessed executive function using the following two psychological tests: the Trail Making Test (TMT, parts A and B) $[27,28]$ and the Stroop Test (ST, parts I and II) [29-31]. In both the TMT and ST tests, the less time required to accurately complete the test, the better the performance. The TMT-A is primarily used to examine the cognitive processing speed, and the TMT-B is used to examine executive function $[27,28]$. The ST-I is used as a measure of processing speed, and the ST-II is used as a measure of selective attention and inhibition [29-31].

\subsection{Secondary Outcomes}

\section{Neurological Assessment of Parkinson's Disease Signs}

All individuals with PD were evaluated by an experienced neurologist (investigator from the CN MUW) who was blinded to the tested groups. This investigator specialized in movement disorders using the Hoehn and Yahr scale, the Unified Parkinson's Disease Rating Scale (UPDRS), and the Schwab and England Daily Living Activity Scale [33]. We analyzed the parkinsonian bradykinesia scores of the more affected upper extremity (Brad.-UE $E_{\text {UPRS } 23}$ ) of each patient based on the UPDRS's finger tapping item (item 23). We also analyzed the performance of daily life manual functions

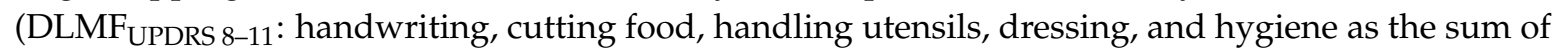
the scores of items 8-11 on the UPDRS). Finally, intellectual and emotional states (Int.Beh. UPDRS 1-4: intellectual impairment, thought disorder, depression, motivation/initiative as the sum of the scores on items 1-4 on the UPDRS) were measured [33]. Based on the Schwab and England Scale, we also assessed the activities of daily living (S\&E DLA scale) [33].

\subsection{Statistical Analysis}

For the bimanual motor control recordings, we obtained the average value of three consecutive trials for each subject. The psychological and neurological tests were conducted once per testing session. All parameters were expressed as group mean and standard deviation values. The Shapiro-Wilk test was performed to estimate the parameters' distribution. The Wilcoxon signed-rank test or Student's $\mathrm{t}$-test (chosen based on the Shapiro-Wilk test and the scale type applied) was performed to test the statistical significance of the differences (if any) in paired-sample comparisons (between the PRE and POST testing sessions). For the unpaired-sample comparisons (between the PD-TR and PD-CO groups), the Mann-Whitney test or Student's t-test (as appropriate) was applied. We also calculated the Cohen effect size ( $d$ value) for both factors (testing session and tested group) for all parameters; a value of 0 indicated no effect, whereas values $>0.2, \sim 0.6$, and $>0.8$ indicated small, moderate, and large effects, respectively. The effect size was calculated as $d=\frac{M_{2}-M_{1}}{S D_{\text {pooled }}}$, where $\mathrm{M}$ is the mean value of the sample, and $S D_{\text {pooled }}$ is the pooled standard deviation, which was calculated as $S D_{\text {pooled }}=\sqrt{\left(S D_{1}^{2}+S D_{2}^{2}\right) / 2}$. 
An $\alpha$ value $\leq 0.05$ was taken as statistically significant for all analyses, which were performed using SPSS Statistics 22.0 software (IBM, Armonk, NY, USA).

\section{Results}

\subsection{Inter-Group Comparison (PD-TR vs. PD-CO) of Clinical and Anthropometric Parameters}

We compared the clinical and anthropometric parameters between the PD-TR and PD-CO groups and found that there were no significant inter-group differences in these parameters (Table 1). The following $p$ and $F$ values were obtained for these comparisons: age $(p=0.483, F=0.513)$; body mass $(p=0.888, F=0.017)$; height $(p=0.870, F=0.027)$; disease onset $(p=0.213, F=1.670)$; disease duration $(p=0.389, F=0.778)$; Hoehn and Yahr scale $(p=0.835, F=0.045)$.

\subsection{Data on Exercise Intensity and Attendance at AIT Testing Sessions}

The average values for $\% \mathrm{HR}_{\max }$, cadence, and power attained in the 24 AIT sessions for the fast and slow phases were as follows: \%HR $\max 68 \pm 10$ vs. $62 \pm 9$ bpm; cadence $69 \pm 13$ vs. $42 \pm 5$ rpm, and power $38 \pm 33$ vs. $22 \pm 19 \mathrm{~W}$. The average reported RPE values for the fast phase was 18, i.e., very hard, and for the slow phase, 14, i.e., somewhat hard.

Patients from the PD-TR group attended, on average, $23.44 \pm 0.73$ out of the 24 AIT sessions ( $97.66 \%$ attendance) with complete attendance ( $24 / 24$ sessions) by six patients, participation in $23 / 24$ sessions by three patients, and participation in 22/24 sessions by one patient. All 20 patients underwent all assessments in the PRE and POST testing sessions (performed in spring: March-June), and all primary and secondary outcomes from these assessments were finally analyzed.

\subsection{Bimanual Motor Control Outcomes}

A significant improvement was observed in the POST vs. PRE comparison in the PD-TR group for the automatic adjustment of GF to generate LF, as reflected by the shortened time and increased rate of GF development in the manipulating hand (time GFman dev and rate GFman dev, respectively) (Figure 3A,B; $p<0.05$, Cohen's d value indicated large and moderate effect sizes, respectively, Table 2). No inter-session differences were observed in the PD-CO group for these parameters (Figure 3A,B; $p>0.05$, Table 2).

Additionally, in the PD-TR group, in the POST vs. PRE comparison, we noted an improvement in automatic inter-limb coordination, as reflected by the shortened time of delay between the initiation of the grip force development in the manipulating hand and that in the stabilizing hand (GFs del man-stab) (Figure 3C; $p<0.05$, Cohen's d value indicated a large effect size, Table 2), and no inter-session differences were observed in the PD-CO group (Figure 3C; $p>0.05$, Table 2). The values of time GFman dev, rate GFman dev, and GFs del man-stab (Figure 3A-C, respectively) did not differ between the PD-TR and PD-CO groups during the PRE testing $(p>0.05$, Table 2$)$ but worsened in the PD-CO group compared to the PD-TR group during the POST testing session $(p<0.05$, Cohen's d value indicated a large effect size, Table 2).

Importantly, the additionally analyzed parameters, i.e., the GFman, 100\% LF, 20\% LF, time $20 \%$ LF dev, and rate 20\% LF dev did not differ between the PRE and POST testing sessions, either in the PD-TR group or in the PD-CO group $(p>0.05)$ and did not differ between the PD-TR and PD-CO groups during either the PRE or POST testing sessions $(p>0.05)$ (Figure 3D-H; Table 2). 

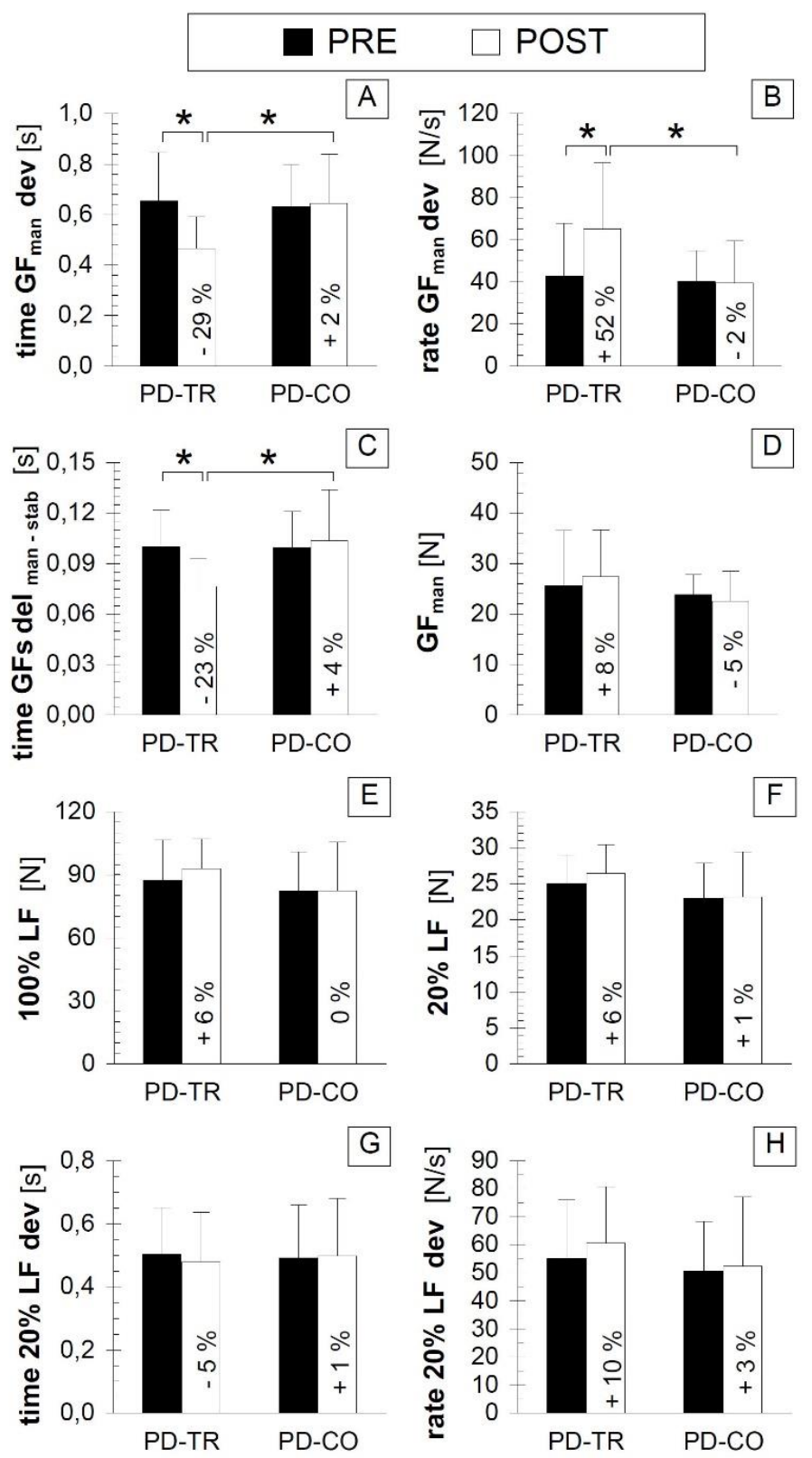

Figure 3. Comparison of the bimanual motor control outcomes between the two testing sessions and the two tested groups. (A) panel A presenting the values of time GFman dev; (B) panel B presenting the values of rate GFman dev; (C) panel C presenting the values of time GFs del man-stab; (D) panel D presenting the values of GFman; (E) panel E presenting the values of $100 \% \mathrm{LF}$; $(\mathbf{F})$ panel F presenting the values of $20 \% \mathrm{LF}$; (G) panel G presenting the values of time $20 \% \mathrm{LF} \mathrm{dev}$; $(\mathbf{H})$ panel $\mathrm{H}$ presenting the values of rate $20 \% \mathrm{LF}$ dev. Abbreviations: PRE—-testing session before the eight weeks of training; POST—testing session after the eight weeks of training; PD-TR_Parkinson's disease patients from the training group; PD-CO_Parkinson's disease patients from the control group; GFman-peak value of grip force in the manipulating hand during the $20 \%$ load force trial; time GFman dev-time taken for GFman development; rate GFman dev—rate of GFman development; time GFs del man-stab — time delay between the onset of grip force development in the manipulating hand and that in the stabilizing hand; $100 \%$ LF- the value of achieved maximal load force; $20 \%$ LF-the peak value of developed LF during the trial of 20\% LF; time $20 \%$ LF dev-the time taken for $20 \%$ LF development; rate $20 \%$ LF dev-the rate of $20 \%$ LF development; the \% value inserted into the bar of the POST session indicates the percentage value of the change between the POST and PRE testing sessions; *-statistically significant inter-testing session or inter-group difference at the $p \leq 0.05$ level. 
Table 2. Significance $(p)$ and effect size (d) values for the parameter comparisons between the testing sessions (POST vs. PRE) and the tested groups (PD-TR, $n=10$ vs. PD-CO, $n=10$ ).

\begin{tabular}{|c|c|c|c|c|c|}
\hline \multicolumn{2}{|c|}{ Parameters } & \multicolumn{2}{|c|}{ POST vs. PRE Comparison } & \multicolumn{2}{|c|}{$\begin{array}{l}\text { PD-TR vs. PD-CO } \\
\text { Comparison }\end{array}$} \\
\hline & & PD-TR & PD-CO & PRE & POST \\
\hline \multirow{8}{*}{$\begin{array}{c}\text { Bimanual } \\
\text { Motor Control } \\
\text { Outcomes }\end{array}$} & time GFman dev & $\begin{array}{l}p=0.013 * \\
d=-1.161\end{array}$ & $\begin{array}{l}p=0.508 \\
d=0.065\end{array}$ & $\begin{array}{c}p=0.821 \\
d=-0.113\end{array}$ & $\begin{array}{c}p=0.025^{*} \\
\mathrm{~d}=1.097\end{array}$ \\
\hline & rate GFman dev & $\begin{array}{l}p=0.013^{*} \\
\mathrm{~d}=0.781\end{array}$ & $\begin{array}{c}p=0.816 \\
d=-0.051\end{array}$ & $\begin{array}{c}p=0.793 \\
d=-0.119\end{array}$ & $\begin{array}{l}p=0.044^{*} \\
d=-0.970\end{array}$ \\
\hline & time GFs del man-stab & $\begin{array}{l}p=0.020 * \\
d=-1.183\end{array}$ & $\begin{array}{l}p=0.592 \\
d=0.152\end{array}$ & $\begin{array}{c}p=0.993 \\
d=-0.004\end{array}$ & $\begin{array}{l}p=0.023 * \\
\mathrm{~d}=1.108\end{array}$ \\
\hline & GFman & $\begin{array}{l}p=0.148 \\
\mathrm{~d}=0.189\end{array}$ & $\begin{array}{c}p=0.288 \\
d=-0.252\end{array}$ & $\begin{array}{c}p=0.646 \\
d=-0.209\end{array}$ & $\begin{array}{c}p=0.173 \\
d=-0.635\end{array}$ \\
\hline & $100 \% \mathrm{LF}$ & $\begin{array}{l}p=0.232 \\
d=0.304\end{array}$ & $\begin{array}{l}p=0.993 \\
d=0.001\end{array}$ & $\begin{array}{c}p=0.534 \\
d=-0.284\end{array}$ & $\begin{array}{c}p=0.246 \\
d=-0.536\end{array}$ \\
\hline & $20 \%$ LF & $\begin{array}{l}p=0.275 \\
d=0.357\end{array}$ & $\begin{array}{l}p=0.213 \\
d=0.026\end{array}$ & $\begin{array}{c}p=0.330 \\
d=-0.448\end{array}$ & $\begin{array}{c}p=0.186 \\
d=-0.619\end{array}$ \\
\hline & time $20 \%$ LF dev & $\begin{array}{c}p=0.449 \\
d=-0.153\end{array}$ & $\begin{array}{l}p=0.725 \\
\mathrm{~d}=0.034\end{array}$ & $\begin{array}{c}p=0.880 \\
d=-0.068\end{array}$ & $\begin{array}{l}p=0.809 \\
\mathrm{~d}=0.110\end{array}$ \\
\hline & rate $20 \% \mathrm{LF}$ dev & $\begin{array}{l}p=0.123 \\
d=0.269\end{array}$ & $\begin{array}{l}p=0.645 \\
d=0.076\end{array}$ & $\begin{array}{c}p=0.705 \\
d=-0.223\end{array}$ & $\begin{array}{c}p=0.424 \\
d=-0.365\end{array}$ \\
\hline \multirow{4}{*}{$\begin{array}{l}\text { Psychological } \\
\text { Outcomes }\end{array}$} & TMT-A & $\begin{array}{c}p=0.083 \\
d=-0.767\end{array}$ & $\begin{array}{c}p=0.838 \\
d=-0.055\end{array}$ & $\begin{array}{l}p=0.650 \\
d=0.057\end{array}$ & $\begin{array}{l}p=0.055 \\
\mathrm{~d}=0.918\end{array}$ \\
\hline & TMT-B & $\begin{array}{c}p=0.216 \\
d=-0.553\end{array}$ & $\begin{array}{l}p=0.722 \\
d=0.082\end{array}$ & $\begin{array}{c}p=0.558 \\
d=-0.267\end{array}$ & $\begin{array}{l}p=0.359 \\
d=0.421\end{array}$ \\
\hline & ST-I & $\begin{array}{l}p=0.751 \\
d=0.097\end{array}$ & $\begin{array}{l}p=0.566 \\
d=0.000\end{array}$ & $\begin{array}{c}p=0.363 \\
d=-0.336\end{array}$ & $\begin{array}{c}p=0.401 \\
d=-0.385\end{array}$ \\
\hline & ST-II & $\begin{array}{l}p=0.007^{*} \\
d=-0.953\end{array}$ & $\begin{array}{l}p=0.140 \\
d=0.136\end{array}$ & $\begin{array}{c}p=0.593 \\
d=-0.244\end{array}$ & $\begin{array}{l}p=0.073 \\
d=0.853\end{array}$ \\
\hline \multirow{4}{*}{$\begin{array}{c}\text { Neurological } \\
\text { Outcomes }\end{array}$} & Brad.-UEUPDRS 23 & $\begin{array}{l}p=0.015^{*} \\
d=-2.108\end{array}$ & $\begin{array}{l}p=0.107 \\
d=0.653\end{array}$ & $\begin{array}{c}p=0.354 \\
d=-0.537\end{array}$ & $\begin{array}{c}p=0.003 * \\
\mathrm{~d}=1.735\end{array}$ \\
\hline & DLMFUPDRS 8-11 & $\begin{array}{l}p=0.004 * \\
d=-1.643\end{array}$ & $\begin{array}{l}p=0.616 \\
d=0.211\end{array}$ & $\begin{array}{c}p=0.242 \\
d=-0.528\end{array}$ & $\begin{array}{l}p=0.309 \\
d=0.646\end{array}$ \\
\hline & Int.Beh. UPDRS 1-4 & $\begin{array}{l}p=0.005^{*} \\
d=-1.214\end{array}$ & $\begin{array}{l}p=0.279 \\
d=0.195\end{array}$ & $\begin{array}{c}p=0.331 \\
d=-0.447\end{array}$ & $\begin{array}{l}p=0.122 \\
d=0.726\end{array}$ \\
\hline & S\&E DLA & $\begin{array}{l}p=0.059 \\
\mathrm{~d}=0.522\end{array}$ & $\begin{array}{c}p=0.317 \\
d=-0.300\end{array}$ & $\begin{array}{l}p=0.155 \\
d=0.526\end{array}$ & $\begin{array}{c}p=0.419 \\
d=-0.339\end{array}$ \\
\hline
\end{tabular}

Abbreviations: PRE—-testing session before the eight weeks of training; POST—-testing session after the eight weeks of training; PD-TR-Parkinson's disease patients from the training group; PD-CO-Parkinson's disease patients from the control group; GFman - peak value of grip force in the manipulating hand during the $20 \%$ load force trial; time GFman dev—time taken for GFman development; rate GFman dev—rate of GFman development; time GFs del man-stab - time delay between the onset of GF development in the manipulating hand and that in the stabilizing hand; $100 \%$ LF-the achieved maximal value of load force; $20 \%$ LF-the peak value of developed LF during the $20 \% \mathrm{LF}$ trial; time $20 \%$ LF dev-the time taken for 20\% LF development; rate $20 \%$ LF dev-the rate of $20 \%$ LF development; TMT-A—part A of the Trail Making Test; TMT-B—part B of the Trail Making Test; ST-I—part I of the Stroop Test; ST-II-part II of the Stroop Test; UPDRS—Unified Parkinson's Disease Rating Scale; Brad.-UE UPDRS 23 — bradykinesia of the upper extremity based on point 23 from the UPDRS; DLMF UPDRS 8-11-daily life manual functions based on the sum of points 8-11 from the UPDRS; Int.Beh. UPDRS 1-4 -intellectual and emotional state based on the sum of points 1-4 from the UPDRS. S\&E DLA scale-Schwab and England Daily Living Activity Scale; $p$-significance value of the inter-testing session or inter-group comparison; $d$ - the Cohen effect size value for the both factors (testing session and tested group); a value of 0 indicated no effect, whereas values $>0.2, \sim 0.6$, and $>0.8$ indicated small, moderate, and large effects, respectively; ${ }^{*}$ statistically significant inter-testing session or inter-group difference at the $p \leq 0.05$ level. 


\subsection{Psychological Cognitive Outcomes}

The ST-II values (Figure 4) were significantly improved in the PD-TR group in the POST vs. PRE comparison $(p<0.05$, Cohen's d value indicated a large effect size, Table 2$)$ but did not change in the PD-CO group $(p>0.05$, Table 2$)$ and did not differ significantly between the PD-TR and PD-CO groups during either the PRE or POST testing sessions ( $p>0.05$, Table 2$)$. However, we would like to underline that there was a clear tendency towards a shorter time taken for ST-II performance in the PD-TR vs. PD-CO in the POST testing session; namely, there was a high Cohen's " $d$ " value $(\mathrm{d}=0.853)$ showing a large effect size for this comparison and a $p$ value close to the $\alpha \leq 0.05$ level $(p=0.073)$.

No difference was observed in the TMT-A, TMT-B, or ST-I values between the PRE and POST testing sessions in either the PD-TR group or the PD-CO group $(p>0.05)$ or between the PD-TR and PD-CO groups during the PRE or the POST testing session $(p>0.05)$ (Figure 4A-C; Table 2). However, notably, a clear tendency toward lower values at POST testing compared with at PRE testing was observed for the TMT-A and TMT-B values in the PD-TR group (Figure 4A,B; Table 2).

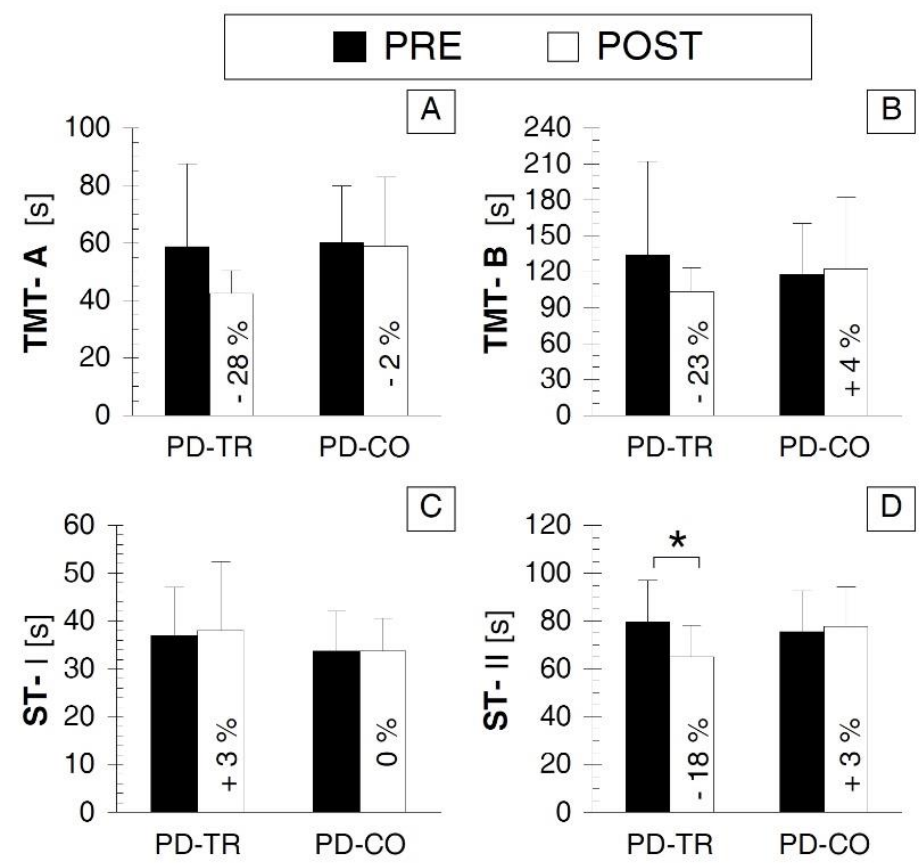

Figure 4. Comparison of psychological cognitive outcomes between the two testing sessions and the two tested groups. (A) panel A presenting the values of TMT-A; (B) panel B presenting the values of TMT-B; (C) panel C presenting the values of ST-I; (D) panel D presenting the values of ST-II. Abbreviations: PRE—testing session before the eight weeks of training; POST—testing session after the eight weeks of training; PD-TR-Parkinson's disease patients from the training group; PD-CO-Parkinson's disease patients from the control group; TMT-A-part A of the Trail Making Test; TMT-B - part B of the Trail Making Test; ST-I—part I of the Stroop Test; ST-II-part II of the Stroop Test; *-statistically significant inter-testing session or inter-group difference at the $p \leq 0.05$ level; the \% value inserted into the bar of the POST session indicates the percentage value of the change between the POST and PRE testing sessions.

\subsection{Neurological Outcomes}

The Brad.-UE $E_{\text {UPDRS } 23}$ (Figure 5A) was improved in the PD-TR group in the POST vs. PRE comparison ( $p<0.05$, Cohen's d value indicated a large effect size, Table 2$)$ but did not significantly change in the PD-CO group ( $p>0.05$, Table 2$)$ and did not differ between the PD-TR and PD-CO groups during PRE testing ( $p>0.05$, Table 2$)$ but was lower in the PD-TR group than in the PD-CO group during POST testing ( $p<0.05$, Cohen's d value indicated a large effect size, Table 2$)$. The DLMF ${ }_{\text {UPDRS } 8-11}$ and Int.Beh. UPDRS 1-4 (Figure 5B,C, respectively) were improved according to the 
POST vs. PRE comparison ( $p<0.05$, Cohen's d value indicated a large effect size, Table 2$)$ in the PD-TR group but did not change in the PD-CO group $(p>0.05$, Table 2$)$ and did not differ between the PD-TR and PD-CO groups during either the PRE or POST testing sessions ( $p>0.05$, Table 2$)$. The S\&E DLA scale value (Figure 5D) did not differ between the PRE and POST testing sessions either in the PD-TR group or in the PD-CO group ( $p>0.05$, Table 2$)$ and did not differ between the PD-TR and PD-CO groups during the PRE or POST testing sessions ( $p>0.05$, Table 2$)$.

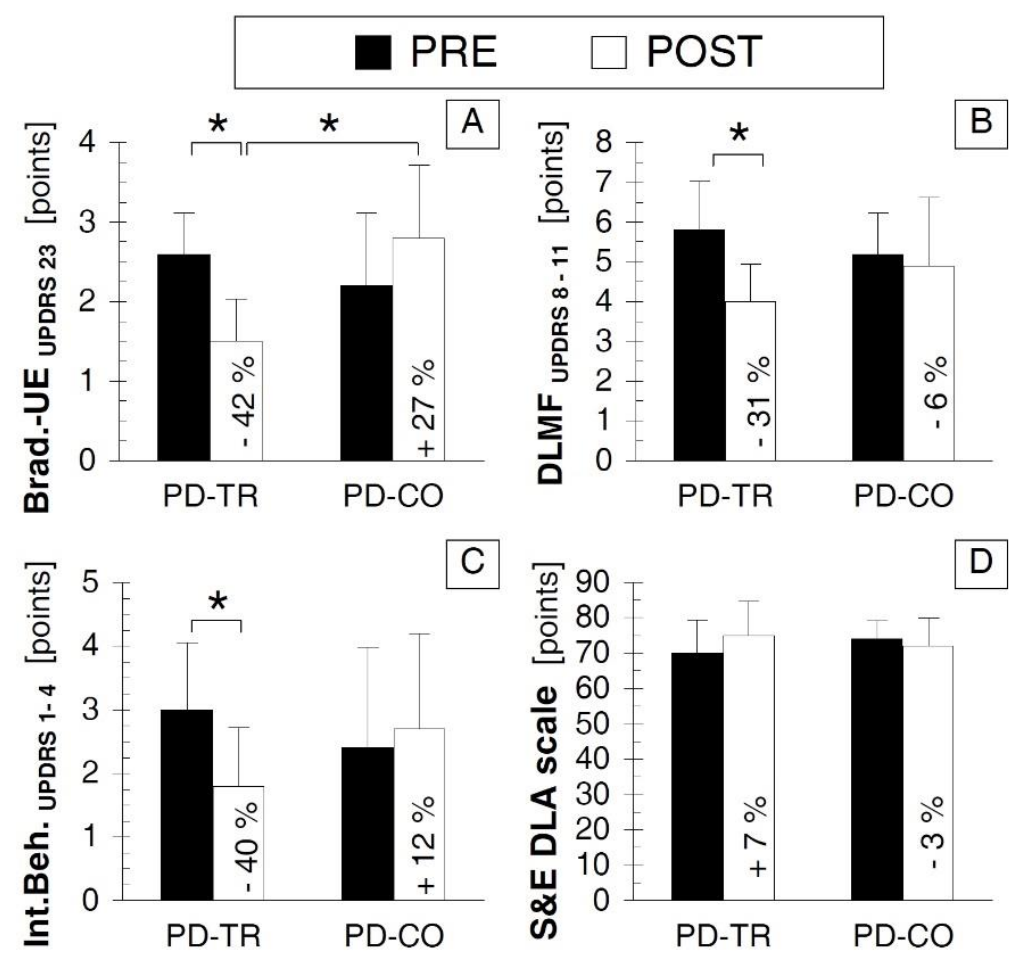

Figure 5. Comparison of neurological outcomes between the two testing sessions and two tested groups. (A) panel A presenting the values of Brad.-UE $E_{\text {UPDRS 23; }}$ (B) panel B presenting the values of

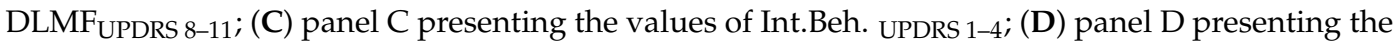
values of S\&E DLA scale. Abbreviations: PRE—-testing session before the eight weeks of training; POST—-testing session after the eight weeks of training; PD-TR—Parkinson's disease patients from the training group; PD-CO-Parkinson's disease patients from the control group; UPDRS-Unified Parkinson's Disease Rating Scale; Brad.-UE UPDRS 23-bradykinesia of the upper extremity based on

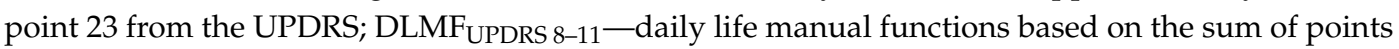
8-11 from the UPDRS; Int.Beh. UPDRS 1-4 -intellectual and emotional state based on the sum of points 1-4 from the UPDRS; S\&E DLA scale-Schwab and England Daily Living Activity Scale; *-statistically significant inter-testing session or inter-group difference at the $p \leq 0.05$ level; the $\%$ value inserted into the bar of the POST session indicates the percentage value of the change between the POST and PRE testing sessions.

\section{Discussion}

Our results show that following the 8-week moderate intensity AIT program, individuals with PD exhibited improved psychomotor behaviors, reflected by their bimanual motor control, executive function, and neurological symptoms evaluation. Our findings provide further evidence for the benefits of exercise but additionally introduce moderate intensity aerobic interval training regimen on the cycle ergometer as a promising physical training modality for PD patients. 


\subsection{Why AIT May Be An Advantageous Treatment Approach for PD}

Previously published human studies $[14,16,17,21,22]$ demonstrated the beneficial effects of continuous intensive training protocols on the motor and non-motor aspects of Parkinson's disease, but the current study is the first randomized controlled study to present a positive generalized effect with a moderate intensity aerobic interval training (AIT) regimen on a cycle ergometer. Alberts et al. [36] showed that high intensity aerobic continuous pedaling on a tandem bicycle causes a hemodynamic effect in the basal ganglia (evaluated with functional magnetic resonance imaging) in trained PD patients. Like the continuous regimen reported by Alberts et al. [36], our moderate intensity AIT may have caused greater blood flux into the basal ganglia as well. This greater blood flux in the basal ganglia may have led to BDNF release by the vascular endothelium, since the endothelial cells secrete BDNF as a response to blood shear stress in the vessels (Prigent-Tessier et al. [37]). Previous studies [24-26] have established that interval training is more enjoyable and effective than continuous exercise programs for non-PD populations. Because the goal is to motivate individuals with PD to adopt a lifelong commitment to exercise, enjoyment is an important factor for improving adherence to exercise [24]. Importantly, other studies have shown that the BDNF increase following interval training is greater than that following continuous regimen training [38,39]. Increased levels of BDNF facilitate neuroplasticity-related motor and cognitive improvements in PD patients, as higher levels of neurotrophic factors (including BDNF) in the basal ganglia have known cytoprotective effects on dopamine-dependent neural structures [40-42]. Importantly, we previously demonstrated increased blood BDNF levels after eight weeks of moderate intensity AIT in PD patients [20,23].

\subsection{AIT-Induced Improvement in Bimanual Motor Control}

We found an AIT-induced improvement in the adjustment of grip force to load force in the manipulating hand and in the inter-limb coordination during the performance of a bimanual anti-phase motor function task in the PD-TR group. Importantly, in terms of the additionally analyzed parameters, i.e., the GFman, $100 \%$ LF, $20 \%$ LF, time $20 \%$ LF dev and rate $20 \%$ LF dev, we did not find any inter-testing session or inter-group differences, which strengthens our interpretation and conclusion regarding the AIT-induced improvement of subconscious (automatic) GF adjustment motor control in the manipulating hand during the conscious performance of bimanual LF generation in the PD-TR group. Other studies $[21,36]$ reported similar improvements (with large effect sizes based on a Cohen's $\mathrm{d}$ value of -1.59) in bimanual dexterity in individuals with PD who participated in continuous forced intensive pedaling on a tandem bicycle. In their studies, the individuals with PD performed eight weeks (three times a week) of a pedaling regime similar to the one used in our study (80-90 rpm or 30\% faster than their volitional speed). Importantly, anti-phase bimanual performance has been identified as a PD-related deficit [2-6]. The neural substrates of bimanual motor coordination and feed forward control to adjust grip force to load force are dopamine-dependent extra pyramidal structures (striatum) and cortical areas (pre-motor areas) [2-5]. In our study, the AIT-induced changes in the subconscious (automatic) adjustment of GF during the conscious performance of the bimanual LF generation task are likely related to an improvement in the functioning of this extra pyramidal system, which is responsible for subconscious motor task performance and bimanual coordination.

\subsection{AIT-Induced Improvement in Executive Function}

Our finding of AIT-induced improvement in executive function is consistent with the results reported by Duchesne et al. [22], who showed an increase in Stroop test performance following aerobic exercise. The clear tendency for improvement in other cognitive measures (reflected in the Trail Making Test) in the PD-TR group is consistent with the results of Ridgel al. [43] who found a similar improvement as an effect of passive lower extremity movement during training on a tandem bicycle in PD patients and as a reaction to regular Nordic walking in healthy elderly people [44]. Ridgel et al. [43] suggested that such exercise might cause an increase in cerebral blood flow, leading to neuroplastic 
changes in the CNS and consequently, improved cognitive function in PD patients. Additionally, the results of Tabak et al. [17] support the psychological results of our study, because these authors found that eight weeks of continuous intensive exercise on a cycle ergometer led to improvements in cognitive measures in PD patients. The cognitive functions tested in the present study, namely executive and inhibitory function, depend on the integrity of dopaminergic subcortical and cortical interconnections, such as the connections between the substantia nigra and the striatum, the striatum and the supplementary motor area (SMA), and the striatum and the dorsolateral prefrontal cortex.

\subsection{AIT-Induced Improvement in Motor and Non-Motor Signs of PD}

Our study demonstrated an amelioration of upper extremity bradykinesia and an improvement in daily life manual functions, and mood and intellectual functions in the PD-TR group. This is consistent with results reported by other researchers $[19,21,23,36]$, who found that intensive aerobic exercise on a tandem or standard cycle ergometer improved motor symptoms in PD. It has been suggested that this improvement is related to an exercise-induced increase in BDNF levels in trained patients. Furthermore, the improvement in activities of daily living, mood, emotional state, cognitive function, and overall quality of life with exercise [45] may reflect exercise-induced neuroplastic changes in the CNS. Marusiak et al. [23] reported that an alleviation of parkinsonian rigidity and decreased resting muscle stiffness (measured with myometry) were correlated with an increase in BDNF levels in patients with PD who participated in moderate intensity AIT [23]. In the present study, we found a generalized beneficial effect of moderate intensity AIT on the DA-dependent motor and non-motor signs that are compromised in PD patients [1].

\subsection{Limitations and Implications of Our Findings}

In the present study, we evaluated the generalized effects of moderate intensity AIT on psychomotor behaviors and did not measure the CNS dopaminergic function changes that we considered in our discussion. However, the outcome measures that were chosen were specific to PD-related psychomotor tasks that engage dopamine-dependent cortical and subcortical structures $[2,3,5]$. The beneficial impact of an AIT program on psychomotor behavior in PD provides a basis for the use of AIT as a treatment approach in the overall therapeutic strategy. Better cognitive and motor function may consequently be associated with a milder disease stage and patient ambulatory status [46], which is important from patient quality of life and treatment cost points of view [47]. Thus, our understanding of mechanisms of the influence of AIT on psychomotor function in PD patients has practical relevance. However, to understand the exact neurophysiological mechanisms of these AIT-induced behavioral benefits (psychomotor function improvement), more research using a variety of neuroimaging methods (electroencephalography, functional magnetic resonance imaging, and positron emission tomography) with a bigger sample size (to increase statistical power and findings generalizability) needs to be conducted.

An important limitation of this study is the relatively small sample size. Nevertheless, the appropriate statistical analysis applied by us was able to reveal the effects of AIT on outcome measures even in this relatively small sample size. However, the generalized effects of AIT on psychomotor function in trained patients with PD that we observed based on present comparative analyses warrant further studies with larger sample sizes to allow for more discerning analyses. These future studies will provide evidence-based knowledge about the benefits of moderate intensity AIT that can be generalized for the whole PD patient population and will be a base for implementation of this kind of exercise as a prescribed treatment form that is recommended and funded by the National Health Fund.

\section{Conclusions}

Eight weeks of moderate intensity aerobic interval training by individuals with Parkinson's disease improved psychomotor behaviors, as reflected by bimanual motor control, executive function, and neurological signs of PD. 
Supplementary Materials: The following are available online at http:/ /www.mdpi.com/1660-4601/16/5/880/s1. Supplementary File 1: Supplementary detailed description of bimanual motor control assessment using our custom-made device, and descriptions of data recording, processing, and analysis.

Author Contributions: Conceptualization, J.M., B.E.F., An.J., Ar.J.; Methodology, J.M., K.S., S.B., M.K., K.K.-S., B.K.; Software, J.M., K.S., B.K.; Validation, J.M., B.E.F., An.J., S.B., K.K.-S., Ar.J.; Formal Analysis, J.M., Ar.J.; Investigation, J.M., K.S., S.B., M.K., K.K.-S.; Resources, J.M., S.B., M.K., Ar.J.; Data Curation, J.M., B.E.F., An.J., K.S., S.B., M.K., B.K.; Writing-Original Draft Preparation, J.M.; Writing-Review \& Editing, J.M., B.E.F., An.J., S.B., M.K., K.K.-S., B.K., Ar.J.; Visualization, J.M., B.K.; Supervision, J.M., Ar.J.; Project Administration and Funding Acquisition, J.M.

Funding: This study was supported by a grant: no. 0247/p01/2010/70 awarded to Jarosław Marusiak from the Ministry of Science and Higher Education of Poland.

Acknowledgments: We thank the patients with Parkinson's disease for participation in our study.

Conflicts of Interest: The authors declare no conflict of interest.

\section{References}

1. Galvan, A.; Wichmann, T. Pathophysiology of parkinsonism. Clin. Neurophysiol. 2008, 119, 1459-1474. [CrossRef] [PubMed]

2. Ponsen, M.M.; Daffertshofer, A.; van den Heuvel, E.; Wolters, E.Ch.; Beek, P.J.; Berendse, H.W. Bimanual coordination dysfunction in early, untreated Parkinson's disease. Parkinsonism Relat. Disord. 2006, 12, 246-252. [CrossRef] [PubMed]

3. Rascol, O.; Sabatini, U.; Chollet, F.; Fabre, N.; Senard, J.M.; Montastruc, J.L.; Celsis, P.; Marc-Vergnes, J.P.; Rascol, A. Normal activation of the supplementary motor area in patients with Parkinson's disease undergoing long-term treatment with levodopa. J. Neurol. Neurosurg. Psychiatry 1994, 57, 567-571. [CrossRef] [PubMed]

4. Samuel, M.; Ceballos-Baumann, A.O.; Blin, J.; Uema, T.; Boecker, H.; Passingham, R.E.; Brooks, D.J. Evidence for lateral premotor and parietal overactivity in Parkinson's disease during sequential and bimanual movements. A PET study. Brain 1997, 120, 963-976. [CrossRef] [PubMed]

5. Wu, T.; Wang, L.; Hallett, M.; Li, K.; Chan, P. Neural correlates of bimanual anti-phase and in-phase movements in Parkinson's disease. Brain 2010, 133, 2394-2409. [CrossRef] [PubMed]

6. Haslinger, B.; Erhard, P.; Kämpfe, N.; Boecker, H.; Rummeny, E.; Schwaiger, M.; Conrad, B.; Ceballos-Baumann, A.O. Event-related functional magnetic resonance imaging in Parkinson's disease before and after levodopa. Brain 2001, 124, 558-570. [CrossRef] [PubMed]

7. Watts, R.L.; Lyons, K.E.; Pahwa, R.; Sethi, K.; Stern, M.; Hauser, R.A.; Olanow, W.; Gray, A.M.; Adams, B.; Earl, N.L.; et al. Onset of dyskinesia with adjunct ropinirole prolonged-release or additional levodopa in early Parkinson's disease. Mov. Disord. 2010, 25, 858-866. [CrossRef] [PubMed]

8. Fisher, B.E.; Petzinger, G.M.; Nixon, K.; Hogg, E.; Bremmer, S.; Meshul, C.K.; Jakowec, M.W. Exercise-induced behavioral recovery and neuroplasticity in the 1-methyl-4-phenyl-1,2,3,6-tetrahydropyridine-lesioned mouse basal ganglia. J. Neurosci. Res. 2004, 77, 378-390. [CrossRef] [PubMed]

9. Petzinger, G.M.; Walsh, J.P.; Akopian, G.; Hogg, E.; Abernathy, A.; Arevalo, P.; Turnquist, P.; Vucković, M.; Fisher, B.E.; Togasaki, D.M.; Jakowec, M.W. Effects of treadmill exercise on dopaminergic transmission in the 1-methyl-4-phenyl-1,2,3,6-tetrahydropyridine-lesioned mouse model of basal ganglia injury. J. Neurosci. 2007, 27, 5291-5300. [CrossRef] [PubMed]

10. Vučković, M.G.; Li, Q.; Fisher, B.; Nacca, A.; Leahy, R.M.; Walsh, J.P.; Mukherjee, J.; Williams, C.; Jakowec, M.W.; Petzinger, G.M. Exercise elevates dopamine D2 receptor in a mouse model of Parkinson's disease: In vivo imaging with $\left[{ }^{18} \mathrm{~F}\right]$ fallypride. Mov. Disord. 2010, 25, 2777-2784. [CrossRef] [PubMed]

11. Chalimoniuk, M.; Chrapusta, S.J.; Lukačova, N.; Langfort, J. Endurance training upregulates the nitric oxide/soluble guanylyl cyclase/cyclic guanosine $3^{\prime}, 5^{\prime}$-monophosphate pathway in the striatum, midbrain and cerebellum of male rats. Brain. Res. 2015, 1618, 29-40. [CrossRef] [PubMed]

12. Langfort, J.; Chalimoniuk, M.; Kania, D.; Lukačova, N.; Chrapusta, S.J. Endurance training counteracts MPTP treatment-related changes in midbrain contents of dopamine and dopamine metabolites, and in parvalbumin expression. In Proceedings of the XX World Congress on Parkinson's disease and Related Disorders, Geneva, Switzerland, 8-11 December 2013; p. 135. 
13. Toy, W.A.; Petzinger, G.M.; Leyshon, B.J.; Akopian, G.K.; Walsh, J.P.; Hoffman, M.V.; Vučković, M.G.; Jakowec, M.W. Treadmill exercise reverses dendritic spine loss in direct and indirect striatal medium spiny neurons in the 1-methyl-4-phenyl-1,2,3,6-tetrahydropyridine (MPTP) mouse model of Parkinson's disease. Neurobiol. Dis. 2014, 63, 201-209. [CrossRef] [PubMed]

14. Fisher, B.E.; Wu, A.D.; Salem, G.J.; Song, J.; Lin, C.H.; Yip, J.; Cen, S.; Gordon, J.; Jakowec, M.; Petzinger, G. The effect of exercise training in improving motor performance and corticomotor excitability in people with early Parkinson's disease. Arch. Phys. Med. Rehabil. 2008, 89, 1221-1229. [CrossRef] [PubMed]

15. Fisher, B.E.; Li, Q.; Nacca, A.; Salem, G.J.; Song, J.; Yip, J.; Hui, J.S.; Jakowec, M.W.; Petzinger, G.M. Treadmill exercise elevates striatal dopamine D2 receptor binding potential in patients with early Parkinson's disease. Neuroreport 2013, 24, 509-514. [CrossRef] [PubMed]

16. Shah, C.; Beall, E.B.; Frankemolle, A.M.; Penko, A.; Phillips, M.D.; Lowe, M.J.; Alberts, J.L. Exercise Therapy for Parkinson's Disease: Pedaling Rate Is Related to Changes in Motor Connectivity. Brain. Connect. 2016, 6, 25-36. [CrossRef] [PubMed]

17. Tabak, R.; Aquije, G.; Fisher, B.E. Aerobic exercise to improve executive function in Parkinson disease: a case series. J. Neurol. Phys. Ther. 2013, 37, 58-64. [CrossRef] [PubMed]

18. Tuon, T.; Valvassori, S.S.; Dal Pont, G.C.; Paganini, C.S.; Pozzi, B.G.; Luciano, T.F.; Souza, P.S.; Quevedo, J.; Souza, C.T.; Pinho, R.A. Physical training prevents depressive symptoms and a decrease in brain-derived neurotrophic factor in Parkinson's disease. Brain. Res. Bull. 2014, 108, 106-112. [CrossRef] [PubMed]

19. Uc, E.Y.; Doerschug, K.C.; Magnotta, V.; Dawson, J.D.; Thomsen, T.R.; Kline, J.N.; Rizzo, M.; Newman, S.R.; Mehta, S.; Grabowski, T.J.; et al. Phase I/II randomized trial of aerobic exercise in Parkinson disease in a community setting. Neurology 2014, 83, 413-425. [CrossRef] [PubMed]

20. Zoladz, J.A.; Majerczak, J.; Zeligowska, E.; Mencel, J.; Jaskolski, A.; Jaskolska, A.; Marusiak, J. Moderate-intensity interval training increases serum brain-derived neurotrophic factor level and decreases inflammation in Parkinson's disease patients. J. Physiol. Pharmacol. 2014, 65, 441-448. [PubMed]

21. Ridgel, A.L.; Vitek, J.L.; Alberts, J.L. Forced; not voluntary; exercise improves motor function in Parkinson's disease patients. Neurorehabil. Neural. Repair 2009, 23, 600-608. [CrossRef] [PubMed]

22. Duchesne, C.; Lungu, O.; Nadeau, A.; Robillard, M.E.; Boré, A.; Bobeuf, F.; Lafontaine, A.L.; Gheysen, F.; Bherer, L.; Doyon, J. Enhancing both motor and cognitive functioning in Parkinson's disease: Aerobic exercise as a rehabilitative intervention. Brain. Cogn. 2015, 99, 68-77. [CrossRef] [PubMed]

23. Marusiak, J.; Żeligowska, E.; Mencel, J.; Kisiel-Sajewicz, K.; Majerczak, J.; Zoladz, J.A.; Jaskólski, A.; Jaskólska, A. Interval training-induced alleviation of rigidity and hypertonia in patients with Parkinson's disease is accompanied by increased basal serum brain-derived neurotrophic factor. J. Rehabil. Med. 2015, 47, 372-375. [CrossRef] [PubMed]

24. Bartlett, J.D.; Close, G.L.; MacLaren, D.P.; Gregson, W.; Drust, B.; Morton, J.P. High-intensity interval running is perceived to be more enjoyable than moderate-intensity continuous exercise: Implications for exercise adherence. J. Sports Sci. 2011, 29, 547-553. [CrossRef] [PubMed]

25. Gaesser, G.A.; Angadi, S.S. High-intensity interval training for health and fitness: Can less be more? J. Appl. Physiol. 2011, 111, 1540-1541. [CrossRef] [PubMed]

26. Moholdt, T.T.; Amundsen, B.H.; Rustad, L.A.; Wahba, A.; Løvø, K.T.; Gullikstad, L.R.; Bye, A.; Skogvoll, E.; Wisløff, U.; Slørdahl, S.A. Aerobic interval training versus continuous moderate exercise after coronary artery bypass surgery: A randomized study of cardiovascular effects and quality of life. Am. Heart J. 2009, 158, 1031-1037. [CrossRef] [PubMed]

27. Arbuthnott, K.; Frank, J. Trail making test; part B as a measure of executive control: Validation using a set-switching paradigm. J. Clin. Exp. Neuropsychol. 2000, 22, 518-528. [CrossRef]

28. Sánchez-Cubillo, I.; Periáñez, J.A.; Adrover-Roig, D.; Rodríguez-Sánchez, J.M.; Ríos-Lago, M.; Tirapu, J.; Barceló, F. Construct validity of the Trail Making Test: Role of task-switching; working memory; inhibition/interference control; and visuomotor abilities. J. Int. Neuropsychol. Soc. 2009, 15, 438-450. [CrossRef] [PubMed]

29. Egner, T.; Hirsch, J. The neural correlates and functional integration of cognitive control in a Stroop task. Neuroimage 2005, 24, 539-547. [CrossRef] [PubMed]

30. Van der Elst, W.; Van Boxtel, M.P.; Van Breukelen, G.J.; Jolles, J. The Stroop color-word test: Influence of age; sex; and education; and normative data for a large sample across the adult age range. Assessment 2006, 13, 62-79. [CrossRef] [PubMed] 
31. Zalonis, I.; Christidi, F.; Bonakis, A.; Kararizou, E.; Triantafyllou, N.I.; Paraskevas, G.; Kapaki, E.; Vasilopoulos, D. The stroop effect in Greek healthy population: Normative data for the Stroop Neuropsychological Screening Test. Arch. Clin. Neuropsychol. 2009, 24, 81-88. [CrossRef] [PubMed]

32. Seubert-Ravelo, A.N.; Yáñez-Téllez, M.G.; Salgado-Ceballos, H.; Escartín-Pérez, R.E.; Neri-Nani, G.A.; Velázquez-Osuna, S. Mild Cognitive Impairment in Patients with Early-Onset Parkinson's Disease. Dement. Geriatr. Cogn. Disord. 2016, 42, 17-30. [CrossRef] [PubMed]

33. Fahn, S.; Elton, R.L.; UPDRS program members. Unified Parkinsons Disease Rating Scale. In Recent Developments in Parkinson's Disease; Fahn, S., Marsden, C.D., Goldstein, M., Calne, D.B., Eds.; Macmillan Healthcare Information: Florham Park, NJ, USA, 1987; Volume 2, pp. 153-163.

34. Tanaka, H.; Monahan, K.D.; Seals, D.R. Age-predicted maximal heart rate revisited. J. Am. Coll. Cardiol. 2001, 37, 153-156. [CrossRef]

35. Borg, G.A. Psychophysical bases of perceived exertion. Med. Sci. Sports Exerc. 1982, 14, 377-381. [CrossRef] [PubMed]

36. Alberts, J.L.; Linder, S.M.; Penko, A.L.; Lowe, M.J.; Phillips, M. It is not about the bike; it is about the pedaling: Forced exercise and Parkinson's disease. Exerc. Sport Sci. Rev. 2011, 39, 177-186. [CrossRef] [PubMed]

37. Prigent-Tessier, A.; Quirié, A.; Maguin-Gaté, K.; Szostak, J.; Mossiat, C.; Nappey, M.; Devaux, S.; Marie, C.; Demougeot, C. Physical training and hypertension have opposite effects on endothelial brain-derived neurotrophic factor expression. Cardiovasc. Res. 2013, 100, 374-382. [CrossRef] [PubMed]

38. Afzalpour, M.E.; Chadorneshin, H.T.; Foadoddini, M.; Eivari, H.A. Comparing interval and continuous exercise training regimens on neurotrophic factors in rat brain. Physiol. Behav. 2015, 147, 78-83. [CrossRef] [PubMed]

39. Saucedo Marquez, C.M.; Vanaudenaerde, B.; Troosters, T.; Wenderoth, N. High-intensity interval training evokes larger serum BDNF levels compared with intense continuous exercise. J. Appl. Physiol. (1985) 2015, 119, 1363-1373. [CrossRef] [PubMed]

40. Somoza, R.; Juri, C.; Baes, M.; Wyneken, U.; Rubio, F.J. Intranigral transplantation of epigenetically induced BDNF-secreting human mesenchymal stem cells: Implications for cell-based therapies in Parkinson's disease. Biol. Blood Marrow Transplant. 2010, 16, 1530-1540. [CrossRef] [PubMed]

41. Slevin, J.T.; Gerhardt, G.A.; Smith, C.D.; Gash, D.M.; Kryscio, R.; Young, B. Improvement of bilateral motor functions in patients with Parkinson disease through the unilateral intraputaminal infusion of glial cell line-derived neurotrophic factor. J. Neurosurg. 2005, 102, 216-222. [CrossRef] [PubMed]

42. Ziebell, M.; Khalid, U.; Klein, A.B.; Aznar, S.; Thomsen, G.; Jensen, P.; Knudsen, G.M. Striatal dopamine transporter binding correlates with serum BDNF levels in patients with striatal dopaminergic neurodegeneration. Neurobiol. Aging 2012, 33, 428.e1-428.e5. [CrossRef] [PubMed]

43. Ridgel, A.L.; Kim, C.H.; Fickes, E.J.; Muller, M.D.; Alberts, J.L. Changes in executive function after acute bouts of passive cycling in Parkinson's disease. J. Aging Phys. Act. 2011, 19, 87-98. [CrossRef] [PubMed]

44. Gmiąt, A.; Jaworska, J.; Micielska, K.; Kortas, J.; Prusik, K.; Prusik, K.; Lipowski, M.; Radulska, A.; Szupryczyńska, N.; Antosiewicz, J.; et al. Improvement of cognitive functions in response to a regular Nordic walking training in elderly women-A change dependent on the training experience. Exp. Gerontol. 2018, 104, 105-112. [CrossRef] [PubMed]

45. Reynolds, G.O.; Otto, M.W.; Ellis, T.D.; Cronin-Golomb, A. The Therapeutic Potential of Exercise to Improve Mood; Cognition; and Sleep in Parkinson's Disease. Mov. Disord. 2016, 31, 23-38. [CrossRef] [PubMed]

46. Hsu, T.H.; Liou, T.H.; Chou, K.R.; Chi, W.C.; Yen, C.F.; Liao, H.F.; Tseng, I.J. Large-Scale Assessment of Function and Disability in Patients with Parkinson's Disease Using the Functioning Disability Evaluation Scale-Adult Version. Int. J. Environ. Res. Public Health 2018, 15, 2788. [CrossRef] [PubMed]

47. Findley, L.; Aujla, M.; Bain, P.G.; Baker, M.; Beech, C.; Bowman, C.; Holmes, J.; Kingdom, W.K.; MacMahon, D.G.; Peto, V.; et al. Direct economic impact of Parkinson's disease: A research survey in the United Kingdom. Mov. Disord. 2003, 18, 1139-1145. [CrossRef] [PubMed]

(C) 2019 by the authors. Licensee MDPI, Basel, Switzerland. This article is an open access article distributed under the terms and conditions of the Creative Commons Attribution (CC BY) license (http:/ / creativecommons.org/licenses/by/4.0/). 